\title{
Severe Deterioration of Metabolic Control Caused by Malfunction of a Disposable Insulin Pen Device
}

\author{
Mauro Boronat, PhD, MD, Yaiza Garcia-Delgado, MD, Nuria Pérez-Martín, MD, and \\ Francisco J. Nóvoa, PhD, MD
}

This report describes the case of a 68 -yr-old diabetic woman with severe deterioration of glycemic control caused by the use of a malfunctioning insulin pen device. (J Am Board Fam Med 2008;21:575-6.)

We communicate the case of a 68 -yr-old woman diagnosed with type 2 diabetes with a severe metabolic deterioration caused by the use of a defective insulin pen device.

Diabetes mellitus had been diagnosed 7 years ago and had been managed by her family physician with a combination of glymepiride and insulin glargine (48 units per day). Six weeks before presentation, the patient was switched to a twice-daily regimen of premixed aspart 70/30 (Novomix 30 Flexpen, Novo Nordisk)_-36 units pre-breakfast and 18 units pre-dinner-to achieve further improvement of glycemic control. Three weeks later, she began with symptoms of hyperglycemia along with domiciliary blood glucose readings $>300 \mathrm{mg}$ / $\mathrm{dL}$. According to orders of her physician, the patient scaled insulin dose up to 45 units in the morning and 30 units in the evening. Nevertheless, during the previous week, she attended the hospital Emergency Unit 3 times because of malaise, dizziness, and capillary glucose levels $>500 \mathrm{mg} / \mathrm{dL}$.

This article was externally peer reviewed.

Submitted 2 March 2008; revised 30 April 2008; accepted 5 May 2008.

From the Section of Endocrinology and Nutrition, Hospital Universitario Insular, Las Palmas de Gran Canaria, Spain (MB,YG-D, NP-M, FJN); and Department of Medical and Surgical Sciences, University of Las Palmas, Spain (MB, FJN).

Funding: none.

Conflict of interest: none declared.

Corresponding author: Mauro Boronat, Section of Endocrinology and Nutrition, Hospital Universitario Insular, Avda. Marítima del Sur, s/n, 35016 Las Palmas de Gran Canaria, Spain (E-mail: mboronat@auna.com).

\footnotetext{
See Related Commentary on Page 487.
}

Formal diagnoses of diabetic ketoacidosis and hyperosmolar hyperglycemic nonketotic syndrome were ruled out by serum biochemistry and venous blood gases. The patient did not present symptoms or signs of an intercurrent infection. Leukocyte count, urinalysis, cardiac enzymes, electrocardiogram, and chest radiograph were normal. The patient was discharged after replenishment of fluids and normalization of plasma glucose with intravenous regular insulin infusion. An urgent appointment with our department was scheduled after the third discharge.

The patient's weight was $83 \mathrm{~kg}$ and height was $162 \mathrm{~cm}$. Physical stigmata of insulin resistance were lacking, and examination of insulin injection sites did not reveal lipohypertrophic areas. Simulated use of the insulin pen demonstrated that she knew proper handling of the device, and her injection technique was good, although she had been not trained to prime the pen before every injection. However, when she was required to show her currently used pen, it was obvious that it had a structural fault. The barb at the end of the piston rod was disengaged (Figure 1), so that the piston did not efficiently push to dispense insulin, even when the patient was able to fully depress the button and dose scale reset to zero after the procedure. Although the unworn pens remaining in the cartridge were in perfect condition, the patient refused to continue on the same type of insulin. She was offered a basal bolus regimen, using glargine at bedtime and insulin aspart pre-meals. Hyperglycaemia subsided in the following hours.

Insulin pens devices have became the standard system for insulin delivery among diabetic patients in Europe. They are usually preferred by both patients and physicians over the traditional 


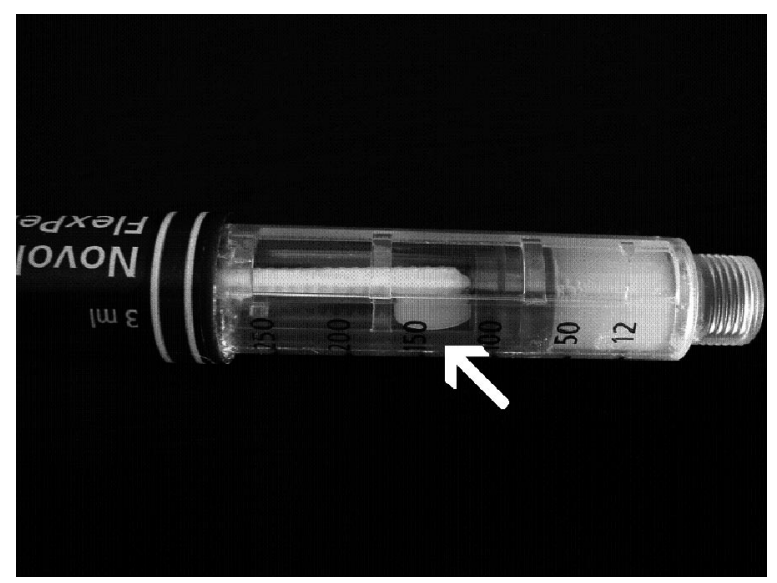

Figure 1. Flexpen used by the patient during the period of metabolic control impairment. Arrow points to the disengaged barb at the tip of the piston rotor.

syringe and vial method, and their use has been demonstrated to improve compliance with insulin therapy. ${ }^{1}$

Accuracy of insulin pens has been long-established by clinical practice. Even though certain data indicate that many patients do not rigorously comply with proper advices of use, ${ }^{2,3}$ evidence of poor metabolic control because of pen malfunction is restricted to isolated case reports. Some of them occurred in patients using reusable insulin pens, ${ }^{4-6}$ in which damage of the delivery mechanism could be more easily explainable by prolonged use, whereas mishandling of the pen or needles by incorrectly trained patients account for the rest of cases. ${ }^{4,7}$ Although it is likely that our patient would had been aware of the pen malfunction if she had strictly followed the manufacturer's instructions (all major manufacturers recommend to prime pens before each injection), the present case illustrates that, albeit exceptionally, disposable insulin pens may bear grave structural defects that make them susceptible to putting the security of patients at risk. Therefore, the possibility of pen malfunction should be considered by both patients and health professionals involved in diabetes care in the presence of an unexplained impairment of metabolic control.

\section{References}

1. Thurman JE. Insulin pen injection devices for management of patients with type 2 diabetes: considerations based on an endocrinologist's practical experience in the United States. Endocr Pract 2007;13: 672-8.

2. Brown A, Steel JM, Duncan C, Duncan A, McBain AM. An assessment of the adequacy of suspension of insulin in pen injectors. Diabet Med 2004;21:604-8.

3. Strauss K, De Gols H, Hannet I, Partanen TM, Frid A. A pan-European epidemiologic study of insulin injection technique in patients with diabetes. Practical Diabetes Int 2002;19:71-6.

4. Albareda M, Balmes L, Wagner A, Corcoy R. Insulin pens and acute deterioration in blood glucose control. Arch Intern Med 1999;159:100.

5. Patel S, Crowley S. My pen ran cold (Horace Walpole). Practical Diabetes Int 1990;7:16.

6. Goksen D, Darcan S, Buyukinan M, Kurt E. Possible problem with Optipen Pro-1: should diabetic patients continue to use this product?. Diabetes Care 2006;29:1710-1.

7. Bhardwaj VR, Metcalfe N, Innes E, Harrison E, Jenkins D. Recurrent diabetic ketoacidosis after changing pen devices for insulin injection. BMJ 2006;332:1259-60. 